\title{
Innovative solutions to reform geriatric oral health in India: Alliance for healthy aging
}

\author{
Kamal Shigli ${ }^{1}$, Sushma S Nayak ${ }^{2}$, Prajna Pramod Nayak ${ }^{3}$, Anita Basavaraj ${ }^{4}$, Shivasakthy M $^{5}$
}

${ }^{1}$ Professor and Head, Department of Prosthodontics, D.Y. Patil Dental School, Lohegaon, Pune, Maharashtra; ${ }^{2}$ Public health dentist, Bangalore, Karnataka; ${ }^{3}$ Assistant Professor, Department of Public Health Dentistry, Manipal College of Dental Sciences, Manipal Academy of Higher Education, Manipal; ${ }^{4}$ Professor and Head, Department of Medicine, Incharge Research Department, Government Medical College, Miraj, and PVPGH Sangli, Maharashtra; ${ }^{5}$ Shivasakthy M, MDS, Professor, Department of Prosthodontics, Indira Gandhi Institute of Dental Sciences, Sri Balaji Vidyapeeth, Puducherry.

\begin{tabular}{|c|c|c|c|c|c|c|c|c|}
\hline Abstract & Introduction & Methodology & Results & Conclusion & References & Citation & \multicolumn{2}{|c|}{ Tables / Figures } \\
\hline \multicolumn{9}{|c|}{ Corresponding Author } \\
\hline \multicolumn{8}{|c|}{$\begin{array}{l}\text { Dr Prajna P. Nayak, Manipal College of Dental Sciences, Manipal Academy of Higher Education, } \\
\text { Manipal. } \\
\text { E Mail ID: nayak.praina@manipal.edu }\end{array}$} & 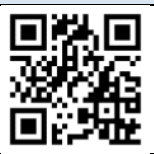 \\
\hline
\end{tabular}

\section{Citation}

Innovative solutions to reform geriatric oral health in India: Alliance for healthy aging. Shigli K, Nayak SS, Nayak PP, Basavaraj A, Shivasakthy M. Indian J Comm Health. 2021;33(1):222-225. https://doi.org/10.47203/IJCH.2021.v33i01.033

Source of Funding: Nil Conflict of Interest: None declared

\section{Article Cycle}

Received: 18/11/2020; Revision: 15/12/2020; Accepted: 15/01/2021; Published: 31/03/2021 This work is licensed under a Creative Commons Attribution 4.0 International License.

\section{Abstract}

Geriatric population is showing an increasing trend, owing to the increased awareness as well as improved healthcare facilities and access. The aging Indian population of the modern-day has diverse and more complex dental needs, unlike the olden-days. Hence, the authors propose innovative strategies to cater to the dental needs of the increasing geriatric population in India. Barriers for provision of geriatric dental care in India are elucidated, which are: lack of geriatric training, access problems and financial issues. Approaches to confront these barriers have been explained. The increasing and compounding dental needs of the aging Indian population requires multifaceted and contemporary strategies.

\section{Keywords}

Geriatric Population; Oral Health; Aging; Geriatric Dental Care

\section{Introduction}

India is ensuing a swift demographic transition. India has already fallen under the category of "greying nation" with $8 \%$ of its population which is 60 years old. Geriatric population of the world is presently around 703 million older persons aged 65 years or more.(1) By 2050, it is estimated to be 2 billion, with $80 \%$ living in developing countries.(2) Increase in longevity means that community will have to bear a greater burden of disease, with gradual transition toward the diseases of elderly and the disabilities associated with aging.(2) In the year 1999,
Government of India launched National Policy on Older persons, primary goal of which was "overall well-being of the elderly, ensuring them a legitimate position in the society".(3)

The management of geriatric patient differs from that of other patients, because of coexistence of various medical conditions, polypharmacy, psychological and neurological issues, social factors and others. Hence, there is a pressing need to translate the longer years of their lives to that of healthier years.(4) 


\section{Importance of oral health}

There is a dynamic relationship between general health and oral health. Extensive tooth loss results in reduced chewing performance affecting food choice; and consequential avoidance of dietary fibre and preference for processed foods and saturated fats.(2) Studies have shown a reduction in risk of pneumonia with an improvement in oral hygiene and care. On the other hand, many systemic diseases like Alzheimer's disease and depression can adversely affect oral health.(2)

Dental needs: Proportion of complete edentulism has reduced substantially and elderly are eager on saving their natural teeth. Yet, this is deterred by impaired mobility impeding access to care, financial difficulties, lack of dental care tradition and negative attitude to oral health. There is a need for clinical and community based intervention programs. The barriers existing for provision of geriatric dental care in India are: 1. lack of geriatric training for students and faculty; 2 . insufficient oral health care provision; 3. access problems and 4 . financial issues. $(5,6,7)$

\section{Proposal Strategies}

1. Measures to tackle lack of geriatric training: Trained work force is the backbone and an essential component of oral health care delivery system. Some of the ways to tackle this issue are:

a) Interdisciplinary training of medical and dental students: Geriatrics \& Gerodontology are missing from the curriculum in Indian medical and dental schools. (6) A very few schools have geriatric training, but limited to 1 - 5 hours of didactic lectures. $(7,8)$ There is a need to incorporate oral health examination in medical curriculum so as to aid in appropriate referrals. In a study done by Haber et al (2015), oral cavity anatomy was added to the traditional medical school head, ears, eyes, nose, and throat (HEENT) examination. An increase in inclusion of oral assessments in the history and physical examination, increased inclusion of oralsystemic health data in the plan documentation, and increased dental primary care referrals were seen. (7) Thus, interprofessional education can teach students, the skills required to assess, triage, educate and refer geriatric patients with oral health problems. b) Training nurses in basics of geriatric dental care: Knowledge of oral health will help in the oral health assessment during routine health check-ups as well as by nurses of homebound elderly so that there can be smart and timely referrals. The nurses need to be sensitized on the routine oral hygiene, denture maintenance, root caries, periodontal diseases, xerostomia, oral mucosal lesions and nutrition for elderly. A study done by R Reed et al (2006) assessed improvement in the oral health knowledge of caregivers at an extended care facility through a series of workshops and 'handson' oral health hygiene demonstrations. Various in-service training programs have been implemented in many developed countries and have evaluated the short-term and long-term effectiveness of these. $(8,9)$

c) Family engagement: Family of elderly population can be educated and motivated for periodic oral health check-ups and encouraging them to follow the routine oral hygiene activities.

d) Institutional capacity building: Government should support for geriatric dentistry teaching and research so as to formulate programs and policies pertinent to the Indian scenario.

2. Measures to improve oral health care provision:

a) Re-orientation of health services: The United Nations has called 2021-2030 as the 'Decade of Healthy Ageing'. In view of this, the Government of India has aimed to create 19 Regional Geriatric Centres in medical colleges and two National Centres for Ageing envisioned to render specialized geriatric care. They are aiming to build the manpower of geriatricians and geriatric care providers. (10) This prospect needs to be utilized to train dentists in geriatric care. The district hospitals and Community Health Centres, are staffed by dentists, who can be trained for better handling the geriatric population. Health talks can be arranged at the nutrition and outpatient clinics periodically. (11)

b) Educating elderly population: Presentation of gerodontology topics in Indian public education through public health workers (Accredited Social Health Assistants [ASHA] 
and multipurpose workers) at the grass root

levels should be increased significantly. They should be trained to provide periodic preventive care instructions and encourage the use of more economical herbal dentifrices for cleaning teeth and dental prostheses. They should promote awareness that poor oral health can have social impacts on quality of life, including self-esteem, comfort, eating, pain and appearance. Focus on preventive oral hygiene care strategies during the initial years of life along with the provision of oral hygiene care aids can help in maintaining a good quality of life in old age.

c) Inter-sectoral co-ordination between oral health and non-communicable disease (NCD) programs (cancer, diabetes, dementia and metabolic syndromes) to promote general health.

d) To train auxiliary staff (dental hygienists, dental nurses) in geriatric dental care such that they can aid in oral health education, prevention of dental caries, screening of oral cancer etc.

\section{Measures to tackle access problems}

a) The Dental Council of India mandates that every dental college should have a fullfledged mobile unit. They provide oral health services in the remote areas. Mobile units can also periodically visit (every week) old age homes and villages to provide dental care. An interdisciplinary team to accompany the mobile unit once in a month.

b) Alliance with local dental associations can play a significant role in reducing the access as well as financial burden. Arrange regular visits to old age homes by dentists to create awareness regarding oral health and its connection with systemic health.

c) Urban slums coverage: Developed countries have old people's home for permanent live-in, grandparents' home for day guests and eat-in-together for those who are living alone to meet their nutritional needs. (3) Similar provisions can be made in the urban slums by setting up geriatric eat-in-together and home for day guests. Here, trained health workers can conduct oral health awareness programs.

\section{Measures to tackle financial burden:}

a) Tie ups with nongovernmental organizations (NGO) to beget Public private partnerships (PPP) for adopting old age homes needs to be encouraged.

b) Adoption of villages: Service clubs can be encouraged to adopt villages so as to take care and fund the geriatric oral health care in the village. Dental colleges in India can actively take up adoption of one village so that interns and final year students can provide care.

c) Dental care provision of the elderly can be shared by State Governments and Dental Colleges (eg: 'Danta Bhagya Yojna' by the Government of Karnataka state provides free dentures to those who are below poverty line aged 60 years and above. In this model, The ASHA workers are given responsibility of identifying the needy senior citizens and linking them with dental colleges. The Government pays a stipulated amount to the dental college). (12)

\section{Conclusion}

The increasing and compounding dental needs of the aging Indian population requires multifaceted and contemporary strategies, not only to improve their oral health but also their quality of life. We have attempted to generate a matrix to provide an expansive structure for the oral health promotion of the elderly.

\section{References}

1. World Population Ageing 2019: Highlights. URL: https://www.un.org/en/development/desa/population/pu blications/pdf/ageing/WorldPopulationAgeing2019Highlights.pdf . [Accessed on 02 Feb 2021]

2. Petersen PE, Yamamoto T. Improving the oral health of older people: the approach of the WHO Global Oral Health Programme. Community Dent Oral Epidemiol. 2005;33(2):81-92. doi: 10.1111/j.1600-0528.2004.00219.x. PMID: 15725170.[PubMed].

3. Paul NS, Asirvatham M. Geriatric health policy in India: The need for scaling-up implementation. J Family Med Prim Care. 2016;5(2):242-247. doi: 10.4103/2249-4863.192333. PMID: 27843821; PMCID: PMC5084541.[PubMed].

4. Dolan TA, Atchison K, Huynh TN. Access to dental care among older adults in the United States. J Dent Educ. 2005;69(9):961-74. PMID: 16141082.[PubMed].

5. Shigli K, Nayak SS, Jirge V, Srinagesh J, Murthy V, Gali S. Current status of gerodontology curriculum in India and other parts of the world: A narrative review. Gerodontology. 2020;37(2):110-131. doi: 10.1111/ger.12461. Epub 2020 Feb 5. PMID: 32022304.[PubMed] 
6. Shigli K, Nayak SS, Sharma S, Nayak V, Nayak PP, Kulkarni P, Manivasakan S. Interprofessional education - a case for Gerodontology training. Gerontol Geriatr Educ. 2020 Nov 9:1-15. doi: 10.1080/02701960.2020.1843453. Epub ahead of print. PMID: 33161893.[PubMed].

7. Haber J, Hartnett E, Allen K, Hallas D, Dorsen C, LangeKessler J, Lloyd M, Thomas E, Wholihan D. Putting the mouth back in the head: HEENT to HEENOT. Am J Public Health. 2015;105(3):437-41. doi: 10.2105/AJPH.2014.302495. Epub 2015 Jan 20. PMID: 25602900; PMCID: PMC4330841.[PubMed].

8. Reed $R$, Broder $H L$, Jenkins $G$, Spivack $E$, Janal MN. Oral health promotion among older persons and their care providers in a nursing home facility. Gerodontology. 2006;23(2):73-8. doi: 10.1111/j.1741-2358.2006.00119.x. PMID: 16677179.[PubMed]

9. Simons D, Baker P, Jones B, Kidd EA, Beighton D. An evaluation of an oral health training programme for carers
[Innovative solutions to...] | Shigli K et al of the elderly in residential homes. $\mathrm{Br}$ Dent $\mathrm{J}$. 2000;188(4):206-10. doi: 10.1038/sj.bdj.4800432. PMID: 10740904. [PubMed].

10. Vardhan Launches 'Decade Of Healthy Ageing' Campaign On International Day For Older Persons. https://www.news18.com/news/india/vardhan-launchesdecade-of-healthy-ageing-campaign-on-international-dayfor-older-persons-2925097.html [Accessed on 02 Feb 2021]

11. Braimoh M, Ogunbodede E, Adeniyi A. Integration of Oral Health into Primary Health Care System: Views of Primary Health Care Workers in Lagos State, Nigeria. J Public Health Afr. 2014;5(1):328. doi: 10.4081/jphia.2014.328. PMID: 28299117; PMCID: PMC5345462.[PubMed].

12. Benjamin N, Umashankar GK, Rani V, Rukmini JN. Evaluation of Danta Bhagya Yojane: A flagship programme of government of Karnataka. IOSR J Dent Med Sci. 2018;17:5660. 